\title{
Characteristics of different ethnic and traditional bread from the perspective of Islamic traditional medicine
}

\author{
Seyed Ahmad Emami ${ }^{1,2}$ and Zahra Sobhani ${ }^{1 *}$ (D)
}

\begin{abstract}
Background: Bread is one of the staple foods throughout the world due to its great nutritional attributes. There are numerous types of bread in different countries that some of them are specific to a particular region or ethnic group. Bread is one of the main sources of the daily dietary pattern of Iranian society and Muslims and it satisfies a large part of daily energy needs. Therefore, it has long been considered by Islamic traditional practitioners. In Islamic traditional medicine (ITM), the first step in treatment is the modification of the diet based on a person's temperament and humors. For this reason, special attention has been paid to bread as a staple food.

Scope and approach: This review described the ethnic bread of Iran and the views of some prominent ITM scientists such as Ibn Beytâr, Ibn Sinâ, Râzi, and Aqili on bread. They described the characteristics of the different types of bread based on the flour used, the amount of bran, and the method of baking with details. Furthermore, they prescribe a specific bread according to the nutritional value of each bread, the speed of digestion, and the temperament of the individual.
\end{abstract}

Key findings and conclusions: Following the recommendations of traditional medicine can improve the bakery industry as well as reduce the side effects of some bread and their related diseases.

Keywords: Dietary behavior, Disease, Flour, Gastrointestinal, Nutrition, Traditional bread

\section{Introduction}

Bread was called "Nan" in Persian and its Arabic word is "Khobz." Bread is one of the oldest man-made foods that its history dates back to human existence on the earth. For the first time, the cereal and grains flour was mixed with water, then obtained dough was baked over the fire. Evidence in Europe presented that people extracted the starch of the root by pounding plants on flat rocks. Then, they placed the starch dough over the fire and baked flat bread $[1,2]$.

Various culinary practices have been used in different cultures and countries for making bread. Ancient Greek scientists noted to different types of bread: bread

\footnotetext{
* Correspondence: Sobhaniz@mums.ac.ir; Sobhaniz911@gmail.com 1 Department of Traditional Pharmacy, School of Pharmacy, Mashhad University of Medical Sciences, Mashhad 91886 17871, Iran Full list of author information is available at the end of the article
}

prepared from sifted or unsifted wheat flour, barley flour and oatmeal flour, bread containing bran, honey, cheese with sesame, and poppy seeds decoration. They also mentioned that in some types of bread the dough was leavened by yeast [3].

The main ingredients used for baking bread are flour, yeast, salt, and water. The quality and sensory perception of the bread will vary according to the baking methods [4].

Nowadays, there are various methods for producing bread around the world [5]. Overall, dough products are separated into several categories based on ingredients used in bread baking recipes. These are including lean and normal bread, sweet and dietetic bread. In the preparation of lean bread, lipids are not used while in normal bread a small amount of sugar, lipid, and milk was used. In sweet bread, in addition to high amounts of sugar, lipid, and milk, some substances such as eggs, spices,

(c) The Author(s). 2020 Open Access This article is licensed under a Creative Commons Attribution 4.0 International License, which permits use, sharing, adaptation, distribution and reproduction in any medium or format, as long as you give appropriate credit to the original author(s) and the source, provide a link to the Creative Commons licence, and indicate if changes were made. The images or other third party material in this article are included in the article's Creative Commons licence, unless indicated otherwise in a credit line to the material. If material is not included in the article's Creative Commons licence and your intended use is not permitted by statutory regulation or exceeds the permitted use, you will need to obtain permission directly from the copyright holder. To view a copy of this licence, visit http://creativecommons.org/licenses/by/4.0/. 
and aromatic substances may be used. Furthermore, the composition of dietetic bakery products varied according to requirements, for instance, gluten-free, sugar-free, low carbohydrate, and low-cholesterol bread [6,7]. It is also worth noting that there are various types of traditional and ethnic bakery products that are made by different methods and materials [8]. Likewise, there are different types of bread in Iran (lavash, barbari, Sangak, Sajji, taftoon) baked according to the customs of different ethnic groups and the climate of the region [9-11]. In addition to the types of bread mentioned above, there is a wide variety of breads listed in ITM.

It should be noted that the basis of ITM is temperament (Mizaj) and all of the things in the world have specific temperaments. There are four humors in the human body that regulating human behavior and the imbalance between them causes diseases. Also the words hot, cold, dry, and moist used in the text describe the quality of each temperament [12].

The main objective of this study is introducing different types of bread in ITM books and different Iranian ethnic groups that were including methods of preparation, usage, therapeutic effects, and their side effects.

\section{Different types of bread in Iran}

The bread was called "Nan" in Persian. Historical research has shown that the word bread is mentioned on Sassanid inscriptions of the third century, and this word can be seen in the Pahlavi texts of the ninth century. There are different types of bread in Iran. Some types of that are more popular and are consumed by people around the country. These are including Sangak, barbari, taftoon, and lavash. Moreover, these breads are baked in traditional, industrial, and semi-industrial bakeries in the cities and are effortlessly accessible. While some other varieties are baked in specific villages and ethnic groups. Bread is also cooked according to the climate of the region with special characteristics. For instance, in cold climate regions, hot condiments such as ginger or even pepper are used in the composition of bread dough. Consequently, there are different types of bread in Iran because it is the principal food of the people and can be found in almost every meal. Additionally, the existence of different ethnicities (Persians, Kurds, Gilakis, Mazandaranis, Lurs, Tats, Talysh, Baloch, Tork, Torkman, Arab, Qashqai, Tabari, Assyrians, Armenians, Georgians, Circassians, and Mandaeans) in Iran has led to a diversity of bread. Various kinds of bread in Iran are classified according to several criteria:

1) Types of flour (usually wheat flour is used in the preparation of bread because it contains gluten which produced spongy and chewable bread). But sometimes corn, rice, barley, oatmeal, and other types of flour are either used alone or in combination with wheat flour to make bread.

2) Baking methods: steam baked, oven baked, tandoori baked, etc.

3) Ingredients added to bread: such as sugar, milk, and oil

However, for bread, a general classification based on size and volume is also considered, which includes bulk, semi-bulk, and flat.

As mentioned, Iranian bread yielded different characteristics in different districts and ethnic groups. For example, more than a dozen types of traditional bread are cooked on different occasions in the cities and villages of North Khorasan province. Residents of this area pay special attention to the quality of bread. In addition, they use some additives and creating a special pattern on the surface of the bread to improve the appearance characteristics. Furthermore, baked bread in this province is sent to other regions as special souvenirs due to its taste. Among the different types of bread which were baked in this province, Yukha bread is considered as a National Cultural Heritage of Iran.

Similarly, there are more than 40 types of bread in Hormozgan province that was located in the southern part of Iran and is covered by the warm waters of the Persian Gulf and the Sea of Oman in a strip approximately $900 \mathrm{~km}$ long. Mahyaweh bread is one of the traditional food in this province (Fig. 1a). When baking this bread, Mahyaweh (which is a liquid obtained from sardines), eggs, and cheese are rubbed on the surface of this thin bread. Baking Mahyaweh bread is one of the skills that women in this province used to earn a living. Likewise, in the northern provinces of Iran, which are located on the coastline of the Caspian Sea, various types of bread are baked. Kelichehnoon bread that was baked in Mazandaran province is not prepared for public use and is mostly used as a ceremonial bread, as well as for longterm storage, especially for travel, shepherds, and herdsmen. This bread is made in the size of a palm or smaller. In the preparation of this bread, rice flour is sometimes used along with wheat flour, which makes the bread crispier. Furthermore, in this bread, various additive, for example, oil, butter, milk, whey, and spices namely turmeric, fennel, and cinnamon are used. Sometimes walnuts and sesame seeds are used in this bread, which is completely tasteful and depends on the facilities.

In Kohgiluyeh and Boyer-Ahmad province, the oldest ethnic bread is made of oak (Fig. 1b). This bread, which is made from oak processing (oak was soaked in water for a week), is useful in treating a variety of gastrointestinal diseases. The color of this bread is dark brown.

Figure 2 depicted the ethnic bread of some regions of Iran which are not common anywhere else. Furthermore, 


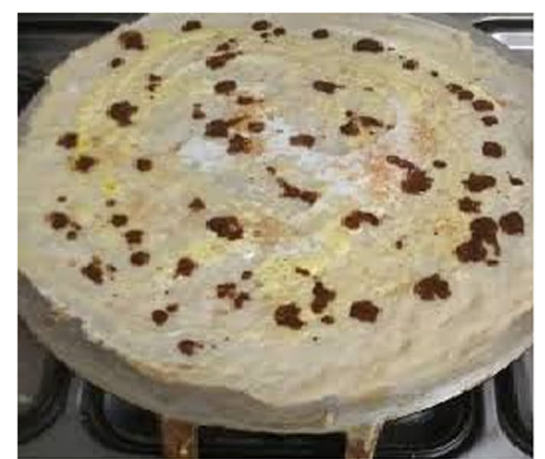

(a)

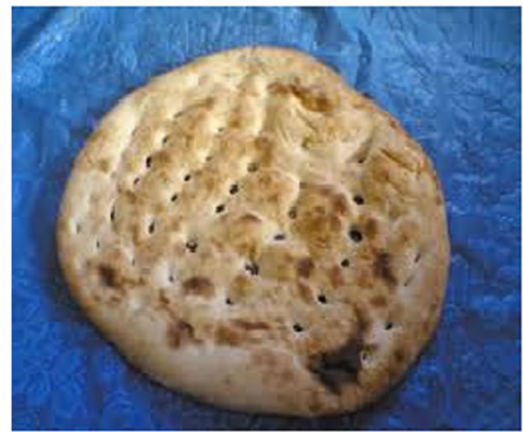

(d)

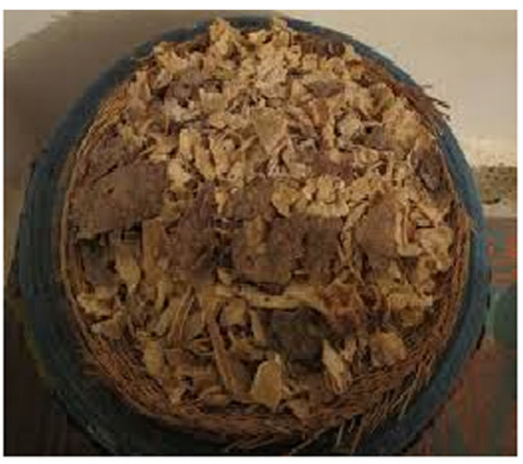

(b)

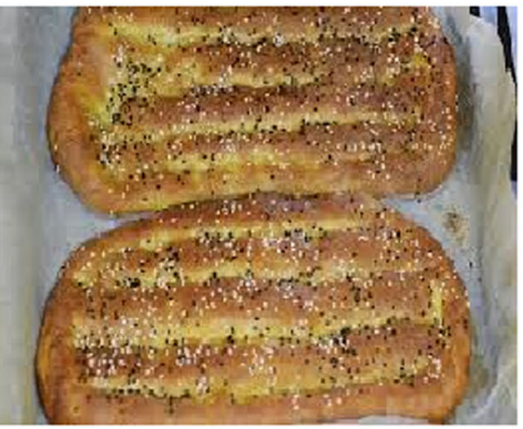

(e)

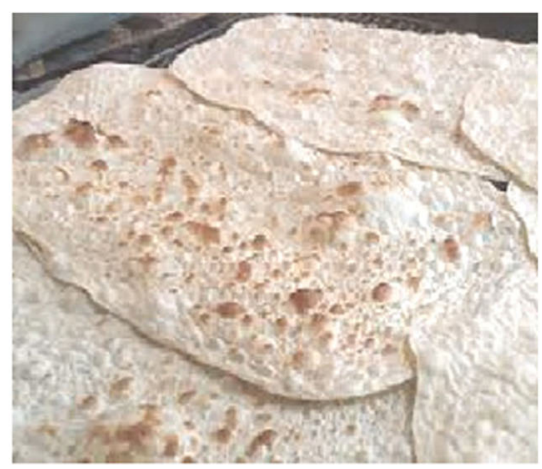

(c)

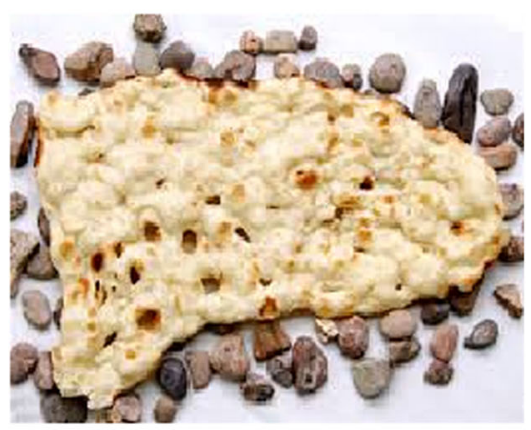

(f)

Fig. 1 a Mahyaweh bread is baked in Hormozgan province. During baking, Mahyaweh (which is a liquid obtained from sardines), eggs and cheese sardines, eggs, and cheese are rubbed on it. $\mathbf{b}$ Oak bread is prepared in Kohgiluyeh and Boyer-Ahmad province after certain processing on oak fruit and has some medicinal properties. c Lavash bread is thin and is made from unleavened dough. $\mathbf{d}$ Taftoon is a flatbread made from wheat flour without bran, water, salt, industrial yeast, or sourdough, and is baked on a hot surface. e Barbari bread hardens after staleness and is baked in two simple and decorated types with sesame seeds. $\mathbf{f}$ Sangak bread, is popular among the people of Iran in terms of taste, flavor, as well as easy digestion and health

these kinds of bread are also used as souvenirs and their production is one of the economic activities to the indigenous people.

As has been noted above, it can be concluded that the variety of traditional and ethnic bread in Iran is great, although the most popular breads found in the entire zones of Iran are as follows:

\section{Lavash bread}

Lavash is thin flatbread and about $3 \mathrm{~mm}$ thick, which was baked from unleavened dough (Fig. 1c). This bread is baked in tandoor, rotating oven, and industrial bakery machine. In the preparation of this bread, flour without bran is used. In appearance, this bread is cooked in rectangular and oval shapes. Lavash bread dries quickly in the open air. However, this dry bread can be stored for a long time and when necessary, it can be consumed like fresh bread by slightly moistening it. This bread has no bran, so it is fattening and also prevents the absorption of iron, calcium, and zinc due to the lack of fermentation. In general, the nutritional value of bread made from white flour without fermentation is negligible.

\section{Taftoon bread}

Taftoon is a flatbread made from wheat flour without bran, water, salt, industrial yeast, or sourdough, and is baked on a hot surface (Fig. 1d). Taftoon bread used to be baked without salt and has been used as a diet bread for patients with high blood pressure. The appearance of taftoon bread is in the shape of a circle with an approximate diameter of $40 \mathrm{~cm}$ and a thickness of 3 to $4 \mathrm{~mm}$. The appearance of taftoon bread is in the shape of a circle with an approximate diameter of $40 \mathrm{~cm}$ and a thickness of 3 to $4 \mathrm{~mm}$. In order to fully bake and heat to reach the surface of the bread circle, holes are made in it with the claws of a hand or a rotating gear, and it is usually baked in two types of traditional and machine-made ovens, in small and large size. In Khorasan province, this bread is baked in ovens that have been dug in the ground.

\section{Barbari bread}

It is a type of bread that is commonly baked in Iran and is produced in both traditional and industrial ways. The name of this bread is derived from the name of the 


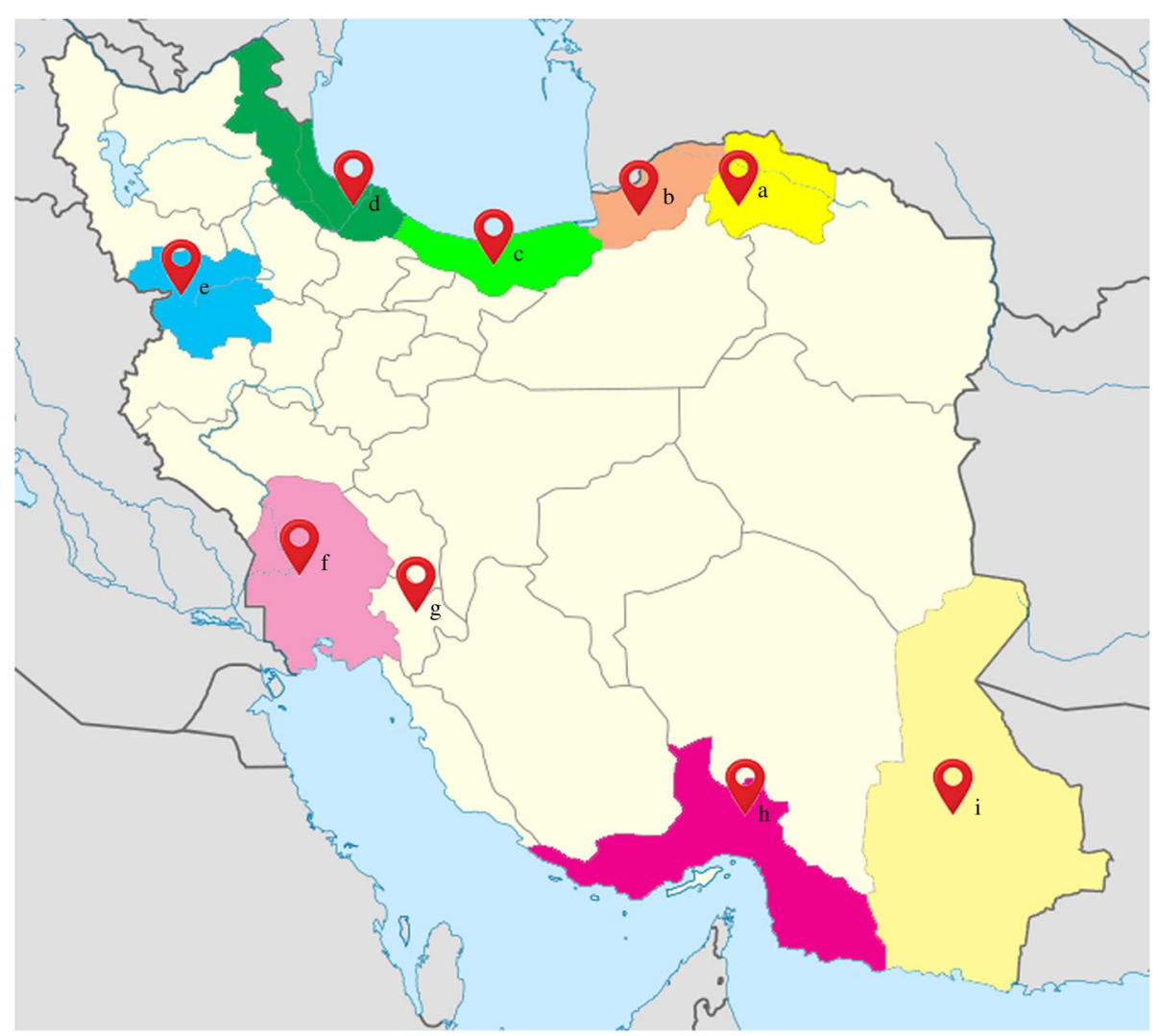

Fig. 2 The special bread of ethnic groups. a Yukha bread is considered as a National Cultural Heritage of Iran and is baked in North Khorasan Province. $\mathbf{b}$ Bishmeh bread is sweet and prepared by Torkamans in Golestan province in the north of Iran. c Kelichehnoon bread that was baked in Mazandaran province as a ceremonial bread, long-term storage, especially for travel, shepherds, and herdsmen. $\mathbf{d}$ Lako bread, the basic flour in this bread is rice flour and is baked in Gilan province that was located in the coastline of Caspian Sea. e Kalaneh bread is baked in Kurdistan province. This bread made of flour, milk, scallions, and butter and baked on a metal pan. $\mathbf{f}$ Seyyah and Shelkin bread are baked in Khuzestan province by Arabs. Seyyah bread made of rice flour and should be eaten warm. Shelkin bread is wheat-based bread and should be eaten with ghee and concentrated syrup of date. $\mathbf{g}$ Oak bread is baked in Kohgiluyeh and Boyer-Ahmad province. $\mathbf{h}$ Mahyaweh bread is baked in Hormozgan province. i Gerdeh, syserk, ponary, and halekary are baked in Sistan and Baluchestan province

Berber tribe (Hazara) who lived on the border between Iran and Afghanistan. At the end of the Qajar period, some barbers started baking this bread in Tehran and spread it. The special taste and smell of this bread are due to the use of a combination of water and a small amount of baking soda, which is rubbed on the bread dough by the baker before baking. Also, while baking this bread, a large amount of sesame is added to it, which makes it very tasty (Fig. 1e).

\section{Sangak bread}

Sangak is a type of bread that is cooked on a bed of Sangak (pebble) in a flat oven (Fig. 1f). It was named Forni bread in ITM. According to history, the inventor of Sangak bread and its tandoor was Bahā' al-Dīn Muhammad ibn usayn al- Āmilī (also known as Sheikh Baha'i(, one of the scholars and scientists who lived in the late sixteenth and early seventeenth centuries in Safavid dynasty. The Sangak bread baking oven has a special shape and its surface is carpeted with pebbles and the bread is baked on hot pebbles. Sangak bread has long been the bread of the aristocracy or the military, and the Sangkis have been seasonal bakeries, mostly baked in the winter and Ramadan, and have never been as widespread as the tandoori bread and taftoon bread in all of Iran. Sangak bread, which is one of the best breads among the people of Iran in terms of taste, flavor, as well as easy digestion and health, is obtained from high quality and healthy flour, pure water, salt, and sourdough. Additionally, Sangak bread is made from wholemeal flour. Sangak bread is delicious in a completely fresh or completely dried form. If this bread stays on the table, its taste will change, conversely, if it is kept in the freezer and then heated with a microwave, its taste and flavor will not change. Abgoosht or Dizi is one of the traditional foods of Iran which is served in traditional Iranian restaurants. Eating this dish with Sangak bread makes it more popular and delicious. Meat, tomato (or tomato paste), and 
chickpeas are used in cooking Abgoosht. A dilute dish made by cooking meat and onions and potatoes and peas that are eaten in two stages. First, the water is mixed with bread crumbs and eaten. The rest of the ingredients can be mashed and consumed with bread, onions, and seasonings such as pickles and vegetables. Eating this dish with Sangak bread makes it more popular and delicious.

Sangak is one of the traditional types of bread that can be decorated with seeds such as sesame seeds, black seed, or a mixture of both to improve its flavor. In the past, poppy seeds were used to, but they are now banned.

\section{Bread in ITM}

In ITM, different types of bread are divided based on a variety of factors such as baking method, different types of grain, and the amount of bran and yeast. The different types of bread and their properties are followed below:

\section{Different kinds of bread based on used grain}

The essential ingredient for bread making is flour. Various grain flours can be used for bakery products. Taken together, the properties of different kinds of bread related to the characteristic of used grain. In addition, other things are needed to make a good quality bread. The kneading and leavening processing should be done well. Moreover, the resultant dough should be cooked in the oven with moderate heat in such a way that it is not unbaked inwardly and burn outside [13, 14].

\section{Wheat bread}

In view of ITM, wheat temperament is hot in the first degree and moderate in dryness and moistness. Wheat flour is the most popular flour for bread making. It is mentioned in Makhzan al-Adwyah; "The best bread is made from high quality wheat flour containing a desirable amount of bran" [13]. Wheat bread is also sorted by the amount of bran. The amount of bran in these three types of bread increased, respectively (nan Samid or Mideh, nan Havari and nan Khoshkar). The Samid bread has the least amount of bran and more nutritional value than other bread but it is slowly digested as well as white bread that was made of fine flour without bran [15]. This bread is flatulent and causes constipation, obstruction in the liver, and produce stone in the kidney. In order to reduce mentioned side effects, it should be used with anise seed, fennel seed, sugar, and sekanjabin bozoori (an oxymel that was prepared from vinegar, sugar or honey, and some seeds such as anise, fennel, and celery) $[15,16]$. Havari bread is one of the best bread and fattens the body. For the preparation of that unwashed whole wheat including bran is used [16, 17]. This bread is deobstruent, besides digested and assimilated quickly. Since these types of bread are flatulent and produce liver obstruction and kidney stones, therefore, people who after consumption of these breads suffered from flatus, constipation, liver obstruction, spleen hardness, and joint pain should use Khoshkar bread with a high amount of leaven agent and borax. In addition, it is useful for them to consume melon seed and celery seeds. However, this bread is laxative and continuous consumption of Khoshkar bread produced dark and thick blood that causes sodavian and melanotic diseases, premature aging, general body weakness, anemia, itching, scabies, and hemorrhoids. It is also harmful to people living in hot and dry climates. In order to reduce the harmful effects of Khoshkar bread, vegetable oil, halva (a kind of dessert or pastry that its basic ingredient is flour), and milk should be used [18]. It should be noted that if this bread is used with salty and spicy foods, its nutritional value will decrease and its side effects will increase [16]. In patients with difficulty swallowing, this bread should be taken with milk, butter, sesame oil, sugar, date, and condensed grape juice [13]. It is not appropriate to consume this bread with honey because honey increases its outflow from the gastrointestinal tract. But if honey is used with a high amount of fat or fatty seeds, it is permissible [16]. In cases where the consumption of this bread is inevitable, in order to increase its nutritional value is recommended to be used along with fats and sweets. Above all, it can prevent intestinal scratching which may be caused by excessive amounts of bran $[16,19,20]$.

\section{Barley bread}

Barley has cold and dry temperament in the first degree and this nature also affects the properties of the barley bread. This bread is flatulent and cools the body's temperament. In addition, it causes colic and damages the joints. To prevent these side effects, it should be consumed with honey, date, lamb rump, and spicy soup. Physicians have suggested that people with cold temperament consume it with broth, sugar, and hydromel to prevent the effects of this bread $[15,16]$.

\section{Chickpea bread}

Chickpea is hot in the first degree and produces hot and moistness in the body, which causes bloating. Chickpea bread is slowly digested and assimilated and hardly gets out of the gastrointestinal tract. To alleviate the adverse effect, this bread should be consumed with high-fat and salty soup. Otherwise, it leads to abdominal and kidney pain. It also produces pellets of feces that cause the difficulty in stool movement through the digestive tract towards the rectum and defecation [14-17]. 


\section{Broad bean bread}

Dried broad bean is cold in the first degree and dry in the second degree. After eating this bread, a high amount of gas was produced in the stomach that not only causes painful bloating but also headaches. Its consumption is forbidden for a person who has bloating in his stomach. In the event that this person has to eat broad bean bread it should be eaten with fatty broth. Additionally, the consumption of mint, pepper, caraway, and vinegar after that prevents from headache $[15,16]$.

\section{Rice bread}

Rice bread is cold and too dry. It is nutritive, tonic, obstruent, and produces thirst [16]. In order to eliminate these disadvantages, people have learned through experience to eat rice bread with salt, fat, and garlic. Salt and garlic prevents colic, and oil and milk are laxative [15, $16]$.

\section{Lentil bread}

Lentil is cold and astringent in nature. As a whole, lentil is flatulent and astringent (especially its husk) and produces the viscous blood and melanotic humor that hardly flows through the cardiovascular system. Consequently, its continuous and long-term consumption can cause of sodavian and melanotic diseases such as varicose veins, melancholia, hemorrhoids, and cancer. In order to prevent the mentioned side effects, it should be consumed with cuscuta, medicinal beer, and myrobalan. Additionally, the digestion of lentil bread is difficult and it causes constipation especially if baked with husk [15, $16]$.

\section{Oak and chestnut bread}

Oak and chestnut are both astringent but the latter is weaker. Oak has cold and dry nature. While there is little hotness in chestnut because it's a little bit sweet. Oak bread is nutritious; however, it is slowly digested and causes constipation. Eating this bread especially longterm consumption of is not beneficial for anyone. The only cure for the disadvantages is the consumption of that with fatty and sweet foods. Chestnut is more nutritious than oak. It also gets out of the gastrointestinal tract faster. While it produces more bloating and gas. To expedite its expulsion from the body, it must be used with laxatives medicine and hydromel $[15,19]$.

\section{Different kinds of bread based on a baking method}

Generally, different methods and equipment are used for baking bread in ancient times and present. Baking method is one of the most important options for bread properties.

\section{Bread baked in a tanoor (Tandoori bread)}

Tanoor (Fig. 3a) is a cylindrical clay oven used for cooking and baking. The tanoor baked bread is the best type of bread and both sides of that are cooked well. It is well digested and assimilated and caused a little bloating. Additionally, it did not produce obstruction and viscosity $[20,21]$.

\section{Bread baked in a furnace (Forni bread)}

A furnace (Fig. $3 \mathrm{~b}$ ) is a cavernous place made of stone, gypsum, or baked clay, and the chimney is placed above it, and inside of that was paved up with fine pebbles to four fingers thick. After setting the fire on one side, the furnace door is closed until it is completely warm and the smoke dissipated $[15,20]$. This bread is not as good as tanoor baked bread, but it comes in second. Its nutritional value is higher than tanoor baked bread. Also, it is suitable and energizing for athletes and people who work hard as farmers $[16,19,21]$.

\section{Bread baked on teak (Sajji bread)}

Teak (Fig. 3c) is a metal plate or pot which bread is baked on it. Most of the time, this bread is thinner and less nutritious than tanoor baked bread. Also, it did not excrete from the digestive tract easily $[20,21]$.

\section{Bread baked on hot ash (Maleh bread)}

This type of bread that was cooked under hot ash is the worst type of bread because it is not fully baked inwardly and caused constipation. Also, it is barely digested and assimilated. It is the driest type of bread and its digestion is slower than others. Therefore, it is useful for laxity stomach with watery phlegm $[20,21]$.

On the whole, the bread contains fenugreek, cumin and nigella seeds are deobstruent, desiccant, and appetizing. In addition, it removes flatulence and its digestion is slow. If poppy seed added to bread, it will be sedative and astringent. Unleavened bread and fine flour bread especially if cooked with milk, oil, and sugar were slowly digested and produced obstruction and flatus. While the bread full of bran is compatible with almost all people with different temperaments. Furthermore, the hot bread produced hotness and dryness in the body. As a result, dried the moisture of the stomach and produced severe thirst. However, it does relieve hunger quickly. On the contrary, cold bread moistens the body. Also, fresh and cold bread, digested more quickly, making the body fat and strong. Dried bread slowly digested in the stomach and all its variants cause thirst $[13,16]$. The bread that washed and dipped in water has a cold nature and suitable for those who have a hot temperament. The washed bread has not a high nutritional value. In addition, it does not produce obstruction and hotness [13]. 


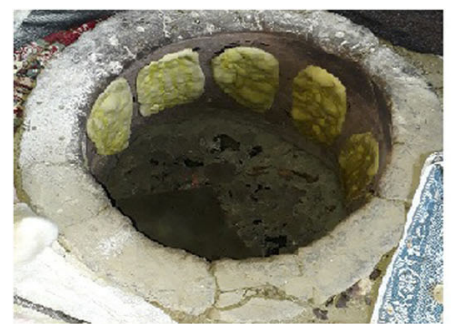

(a)

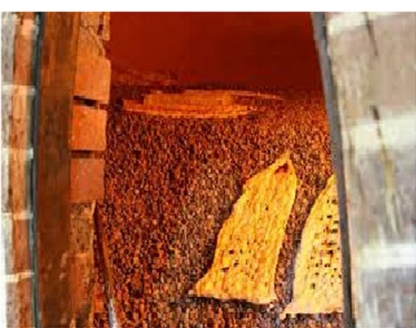

(b)

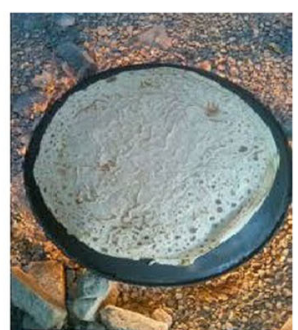

(c)

Fig. 3 a Tanoor is a cylindrical clay oven used for cooking and baking. b A furnace is a cavernous place made of stone, gypsum, or baked clay, and the chimney is placed above it, and inside of that was paved up with fine pebbles to four fingers thick. $\mathbf{c}$ Teak is a metal plate or pot which bread is baked on it

Unleavened bread and less leavened bread with a small amount of salt only suitable for athletes and people who have a lot of physical activity. In comparison, the fully leavened and baked bread is suitable for non-athlete, elderly people, and who recovers from illness [13, 16]. Salty bread and burqa bread (burqa or borax: $\mathrm{Na} 2[\mathrm{~B} 4 \mathrm{O} 5(\mathrm{OH}) 4] \cdot 8 \mathrm{H} 2 \mathrm{O}$ is a chemical formula for borax but burqa al-Khabbazin is different from today's borax, this is what the bakers dissolve it in water and before the bread is baked in the oven, rub it on the bread to make it more beautiful and radiant) have a low nutritional value and quickly assimilated $[16,21]$.

\section{Therapeutic effects of bread}

The plaster made of bread, hydromel with cooling, and smoothing plant extracts is a useful treatment for hot inflammation. Similarly, topical administration of the mixture of bread, water, and salt is a beneficial remedy for psoriasis [19].

The consumption of barley bread treats diarrhea and fever caused by weakness of the stomach. In the same way, rice bread can use for treating biliary and hemorrhagic diarrhea. Additionally, rice bread used as cosmetic agent and makes the face brighter and more beautiful. Applying a face mask made of whole wheat bread with egg white makes the skin clear and smooth $[16,19]$. Furthermore, the topical application of the dough made from dry bread in water prevents the skin of the face from darkening in the sun and wind [22].

Galen said: The sourdough made from wheat flour has a slightly warmer temperament; however, it is cooling and is effective in treating inflammation and swelling. Covering skin abscesses with a dressing made from a combination of sourdough and oil can treat abscesses by opening them and removing pus. Moreover, one of the effective treatments for scorpion stings is to place halffermented dough on the bite site. In this case, the baked dough has better healing effects. Oral consumption of soaked baker's yeast in water with sugar and saffron is useful in treating children's fever [23].
In general, different liniments are made from bread to treat swellings with different characteristics. Fully baked bread is beneficial for treating severe swelling and to treat hot inflammation, it is better to use bread that is slightly baked [24].

In ITM, there are various treatments for sensitive teeth that cause toothache due to cool. For treatment, it is recommended to bite hot bread several times [25].

\section{Conclusion}

In conclusion, an overview of manuscripts of traditional medicine written by prominent physicians such as Avicenna, Râzi, and Ibn Beytâr revealed that they have paid particular attention to food and diet. Razi said: "The indiscriminate use of drugs is extremely pernicious; physicians should treat patients through nutrition as long as they can. Otherwise, first, use simple drugs and then compound drugs."

Bread has always been a popular national daily diet all over the world and the consumption of inappropriate bread causes important side effects. Bread is not only a rich source of energy due to the presence of carbohydrates but also contains proteins, fatty acids, vitamins, and minerals. Therefore, in order to maintain its nutritional value and balance the body's temperament, it is essential that all of its processing steps including flour particle size, kneading, fermentation, and baking are well performed.

In today's human society, people's desire for a healthy lifestyle has increased while paying attention to appearance. This can be improved by applying the recommendations of ITM physicians. For example, in traditional medicine, it is mentioned that the consumption of bread made from very fine white flour has low nutritional value and causes various diseases such as gastrointestinal, liver, and kidney disorders. It is also recommended to use nigella and cumin seed to reduce bloating. Recent studies have revealed that white bread has low nutritional value and high hypoglycemic index [26, 27]. Moreover, it causes non-alcoholic fatty liver, obesity, and cardiovascular disease [28]. On the other hand, it 
has also been proven that nigella and cumin seeds have hypoglycemic effects and reduce blood lipids $[29,30]$.

Eventually, according to traditional medicine recommendations on bread, more research is needed to apply innovations in the optimization process of the bread and bakery industry.

\section{Abbreviation}

ITM: Islamic traditional medicine

\section{Acknowledgements}

This study has been supported by the Deputy of Research of Mashhad University of Medical Sciences.

\section{Authors' contributions}

Seyed Ahmad Emami, Zahra Sobhani. SA. E.: suggested the idea and searched in manuscript textbooks at traditional medicine sources. Z. S.: searched in manuscript textbooks at traditional medicine sources, supervised the research, and co-wrote the paper. Both authors read and approved the final manuscript.

\section{Funding}

Not applicable.

\section{Availability of data and materials}

Not applicable.

\section{Competing interests}

The authors have no conflicts of interest to declare.

\section{Author details}

'Department of Traditional Pharmacy, School of Pharmacy, Mashhad University of Medical Sciences, Mashhad 91886 17871, Iran. ${ }^{2}$ Department of Pharmacognosy, School of Pharmacy, Mashhad University of Medical Sciences, Mashhad, Iran.

Received: 7 January 2020 Accepted: 27 April 2020

Published online: 11 May 2020

\section{References}

1. Mondal A, Datta A. Bread baking-a review. J Food Eng. 2008. https://doi. org/10.1016/j.jfoodeng.2007.11.014.

2. Marchant J, Reuben B, Alcock JP. Bread: a slice of history. United Kingdom: History Press; 2008.

3. Kokoszko M, Jagusiak K, Dybala J. Bread as food and medicament in Oribasius' writings. Studia Ceranea. 2017;18:355-76.

4. Cauvain SP. Breadmaking: improving quality. Sawston: Woodhead Publishing; 2012.

5. Kariluoto S, Vahteristo L, Salovaara H. Effect of baking method and fermentation on folate content of rye and wheat breads. Cereal Chem. 2004. https://doi.org/10.1094/CCHEM.2004.81.1.134.

6. Giannou V, Kessoglou V, Tzia C. Quality and safety characteristics of bread made from frozen dough. Trends Food Sci Tech. 2003;2003. https://doi.org/ 10.1016/S0924-2244(02)00278-9.

7. Gil A, Ortega RM, Maldonado J. Wholegrain cereals and bread: a duet of the Mediterranean diet for the prevention of chronic diseases. Public Health Nutr. 2011. https://doi.org/10.1017/S1368980011002576.

8. Smith JP, Daifas DP, El-Khoury W, Koukoutsis J, El-Khoury A. Shelf life and safety concerns of bakery products-a review. Crit Rev Food Sci Nutr. 2004. https://doi.org/10.1080/10408690490263774.

9. Naghipour D, Amouei A, Nazmara SA. Comparative evaluation of heavy metals in the different breads in iran: a case study of rasht city. Health Scope. 2014. https://doi.org/10.17795/jhealthscope-18175.

10. Khaniki GRJ, Yunesian M, Mahvi AH, Nazmara S. Trace metal contaminants in Iranian flat breads. J Agric Soc Sci. 2005;1(4):301-3.

11. Ghanbari M, Farmani J. Influence of hydrocolloids on dough properties and quality of barbari: an Iranian leavened flat bread. J Agric Soc Sci. 2013;15: 545-55.
12. Sobhani Z, Nami SR, Emami SA, Sahebkar A, Javadi B. Medicinal plants targeting cardiovascular diseases in view of Avicenna. Curr Pharm Design. 2017. https://doi.org/10.2174/1381612823666170215104101.

13. Aqili Alawi Khorâsâni Shirâzi MH. Makhzan al-Adwyah (Drug treasure). Shams Ardakani MR, Rahimi R, Farjadmand F, editors. Tehran: Sabz Arang publisher; 2014. P. 281-304.

14. Râzi MZ. Al-Hâwi fi at-Tibbe (Comprehensive book of medicine), vol. 6. Beirut: Dâr Ehia al-Tourath al-Arabi; 2002. p. 273.

15. Râzi MZ. Manâfe al- Aghdiah wa Dafe Madârehâ. Damascus: Dâr al-Kotob alArabi; 1984. p. 53-8.

16. Ibn Beytâr AA. Al-Jâmee le Mofradât al- Adwyah wa al-Aghdiah (Comprehensive book in simple drugs and foods), vol. 2. Beirut: Dâr alKotob al-Ilamiyah; 2001. p. 191.

17. Tonekâboni MM. Tohfat al- Mo'menin (Rarity of the faithful). Tehran: Shahar Publishers; 2008. p. 606

18. Ansâri Shirâzi AH. Ekhtiyârât Badi ii. Tehran: Pakhshe Razi Private Joint Stock Co; 1993. p. 137.

19. Ibn Sinâ HA. Al-Qânun fi at-Tibbe (Canon of Medicine), vol. 2. Beyrut, Lobnan: Dâr -al Fikr; 2002. p. 910-1.

20. Ahwâzi Arjâni AA. Kâmel al-Sinâh at-Tibbiyah. Qum: Natural Medicine Resuscitation Institution; 2009. Vol. 1.p. 497.

21. Ibn Nafis Qarshi AA. Ash -Shâmel fi at-Tibbe. Abu Dhabi: Cultural Foundation Publications; 1999. Vol. 10. p. 22-36.

22. Râzi MZ. Al-mansouri fi at-Tibbe. Tehran: Tehran University of Medical Sciences; 2008. p. 343.

23. Râzi MZ. Al-mansouri fi at-Tibbe. Tehran: Tehran University of Medical Sciences; 2008. p. 171-2.

24. Râzi MZ. Al-mansouri fi at-Tibbe. Tehran: Tehran University of Medical Sciences; 2008. p. 238.

25. Râzi MZ. Al-mansouri fi at-Tibbe. Tehran: Tehran University of Medical Sciences; 2008. p. 458

26. Shakib MC, Gabrial SG. Post-prandial responses to different bread products based on wheat, barley and fenugreek or ginger or both in healthy volunteers and their effect on the glycemic index of such products. J Am Sci. 2010;6(10):89-96.

27. Udani JK, Singh BB, Barrett ML, Preuss HG. Lowering the glycemic index of white bread using a white bean extract. Nutr J. 2009. https://doi.org/10. 1186/1475-2891-8-52.

28. Georgoulis M, Kontogianni MD, Tileli N, Margariti A, Fragopoulou E, Tiniakos D, Zafiropoulou R, Papatheodoridis G. The impact of cereal grain consumption on the development and severity of non-alcoholic fatty liver disease. Eur J Nutr. 2014. https://doi.org/10.1007/s00394-014-0679-y.

29. Heshmati J, Namazi N, Memarzadeh MR, Taghizadeh M, Kolahdooz F. Nigella sativa oil affects glucose metabolism and lipid concentrations in patients with type 2 diabetes: a randomized, double-blind, placebo-controlled trial. Food Res Int. 2015. https://doi.org/10.1016/j.foodres.2015.01.030.

30. Lemhadri A, Hajji L, Michel JB, Eddouks M. Cholesterol and triglycerides lowering activities of caraway fruits in normal and streptozotocin diabetic rats. J Ethnopharmacol. 2006. https://doi.org/10.1016/j.jep.2006.01.033.

\section{Publisher's Note}

Springer Nature remains neutral with regard to jurisdictional claims in published maps and institutional affiliations.

Ready to submit your research? Choose BMC and benefit from:

- fast, convenient online submission

- thorough peer review by experienced researchers in your field

- rapid publication on acceptance

- support for research data, including large and complex data types

- gold Open Access which fosters wider collaboration and increased citations

- maximum visibility for your research: over $100 \mathrm{M}$ website views per year

At $\mathrm{BMC}$, research is always in progress.

Learn more biomedcentral.com/submission 